\title{
Altered Central Pain Processing in Patients With Chronic Plantar Heel Pain: A Critically Appraised Topic
}

\author{
Dhinu J. Jayaseelan, Cesar Fernandez-de-las-Penas, Taylor Blattenberger, and Dean Bonneau
}

\begin{abstract}
Clinical Scenario: Plantar heel pain is a common condition frequently associated with persistent symptoms and functional limitations affecting both the athletic and nonathletic populations. Common interventions target impairments at the foot and ankle and local drivers of symptoms. If symptoms are predominantly perpetuated by alterations in central pain processing, addressing peripheral impairments alone may not be sufficient. Clinical Question: Do individuals with chronic plantar heel pain demonstrate signs potentially associated with altered central pain processing? Summary of Key Findings: After searching 6 electronic databases (PubMed, CINAHL, Scopus, SportDiscus, Cochrane, and PEDro) and filtering titles based on predetermined inclusion and exclusion criteria, 4 case-control studies were included. All studies scored highly on the Newcastle-Ottawa Scale for quality assessment. Using pressure pain thresholds, each study found decreased pressure pain hypersensitivity locally and at a remote site compared to control groups, suggesting the presence, to some extent, of altered nociceptive pain processing. Clinical Bottom Line: In the studies reviewed, reported results suggest a possible presence of centrally mediated symptoms in persons with plantar heel pain. However, despite findings from these studies, limitations in appropriate matching based on body mass index and measures used suggest additional investigation is warranted. Strength of Recommendation: According to the Oxford Centre for Evidence-Based Medicine, there is evidence level C to suggest chronic plantar heel pain is associated with alterations in central pain processing.
\end{abstract}

Keywords: pain mechanisms, plantar fasciitis, plantar fasciopathy

Plantar heel pain is a highly prevalent condition accounting for between $20 \%$ and $39 \%$ of lower-extremity painful disorders affecting both athletic ${ }^{1,2}$ and nonathletic ${ }^{3}$ populations. Conservative treatment represents the first therapeutic line for this condition. Several interventions, including corticosteroid injections, exercise, extracorporeal shockwave therapy, or manual therapy, are proposed for the treatment of plantar heel pain. However, current evidence is equivocal regarding which treatment is the most effective. ${ }^{4}$ Most treatment approaches proposed for the management of plantar heel pain-for example, corticosteroid injections or extracorporeal shockwave therapy - are mainly based on localized interventions targeting the foot and/or ankle. ${ }^{4}$ Local treatments mainly target peripheral (localized) nociceptive input, although an indirect effect on the central nervous system is also feasible. If plantar heel pain is primarily mediated by peripheral mechanisms, therapeutic strategies targeting tissues potentially related to the peripheral input and local exercises should be encouraged. It has been recently proposed that individuals with plantar heel pain may exhibit altered nociceptive processing involving a hyperexcitability of the central nervous system or inhibition of conditioning pain modulation systems. The presence of an altered nociceptive central pain processing would lead to changes in the clinical reasoning for the management of these patients, because in those individuals primarily mediated by central mechanisms, multimodal integrative

Jayaseelan and Bonneau are with the Department of Health, Human Function, and Rehabilitation Sciences, George Washington University, Washington, DC, USA. Fernandez-de-las-Penas is with the Department of Physical Therapy, Occupational Therapy, Rehabilitation, and Physical Medicine, Universidad Rey Juan Carlos, Alcorcon, Spain. Jayaseelan and Blattenberger are also with Virginia Orthopedic Manual Physical Therapy (VOMPTI), Orthopaedic Residency, Charlottesville, VA, USA. Jayaseelan (dhinuj@gwu.edu) is corresponding author. treatments including physical, psychological, or cognitive and educational approaches should be applied.

Therefore, the purpose of this critically appraised topic was to review current evidence regarding the presence of altered nociceptive central processing in people with plantar heel pain.

\section{Focused Clinical Question}

Do individuals with chronic plantar heel pain demonstrate signs associated with altered central pain processing?

\section{Summary of Search, Best Evidence Appraised, and Key Findings}

Six electronic databases were searched from inception through July 1, 2020, using relevant keywords and Medical Subject Heading $(\mathrm{MeSH})$ terms for studies related to the clinical question, yielding 275 results.

After applying all inclusion and exclusion criteria; 4 studies, all case-control trials, were included in this review. ${ }^{5-8}$

Each study used some form of quantitative sensory testing (QST), typically pressure pain thresholds (PPTs) applied to both local and distant pain-free areas, to detect possible alterations in central pain processing in individuals with chronic plantar heel pain.

\section{Clinical Bottom Line}

The results of 4 well-performed case-control studies suggest altered central pain processing, demonstrated by widespread pressure pain hyperalgesia, may be present in people with plantar heel pain. Other methods of QST did not consistently reveal altered central 
pain processing, suggesting that findings may be test specific. If individuals present clinically with nervous system sensitization, treatment plans directed toward the peripheral pain location may not be as effective as more comprehensive programs also targeting central mechanisms. Clinical assessment of predominant pain mechanisms is warranted in order to inform decision making in this population.

\section{Strength of Recommendation}

According to the Oxford Centre for Evidence-Based Medicine's strength of recommendation, there is evidence Level $\mathrm{C}$ suggesting that chronic plantar heel pain may be associated with altered central pain processing. Level C evidence in this case is the result of level 4 studies (diagnostic case-control designs).

\section{Search Strategy}

The example keywords for each item of the clinical question used during electronic searches are as follows. Specific search strategies were modified as needed for different databases in order to obtain relevant results.

\section{Terms Used to Guide Search Strategy}

- Population-patients with chronic plantar heel pain (plantar fasciitis OR plantar fasciosis OR plantar fasciopathy OR plantar fasci* OR plantar heel pain OR policeman's heel OR policeman's heel)

- Intervention-N/A

- Comparison-healthy controls

- Outcome - evaluation of altered central pain processing (central sensitisation OR central sensitization OR centrally mediated OR nociplastic OR nociplasticity OR pressure pain threshold* OR PPT OR algometry OR hyperalgesia OR hypersensitivity OR allodynia OR quantitative sensory testing OR QST OR windup OR wind-up OR hyperexcitability OR somatosensory)

\section{Sources of Evidence Searched (Number of Results)}

- PubMed $(\mathrm{n}=51)$

- CINAHL $(\mathrm{n}=37)$

- Scopus $(n=33)$

- SportDiscus $(n=16)$

- Cochrane Library $(n=38)$

- PEDro $(n=100)$

\section{Inclusion and Exclusion Criteria}

\section{Inclusion Criteria.}

- Peer-reviewed article, full-text available

- English language

- Clinical diagnosis of plantar heel pain in one or more groups

- Symptom duration $\geq 3$ months

- Clinical assessment of central pain processing was performed

- Control group present

\section{Exclusion Criteria.}

- No plantar heel pain diagnosis

- Acute pain reports $(<3$ mo)

- No full-text available in English (eg, abstract only)

- No outcome measurement of central pain processing

- Single-arm design

\section{Results of Search}

In total, 275 titles were retrieved from electronic searches. After filtering titles based on predetermined criteria, 4 studies reporting on a total of 211 participants were retained for inclusion. Each study used a case-control design, as can be seen in Table 1 . The primary reasons for exclusion were the lack of an assessment of central pain processing (eg, local PPT only) or no control group.

\section{Best Evidence}

The included studies most closely matched the established PICO question of all retrieved titles. Study characteristics, participant demographics, methodology, and results were extracted and are presented in Table 2. Each study was also appraised for quality using the Newcastle-Ottawa Scale. Each study was independently appraised by 2 authors (TB, DB), and in the case of discrepancy, a third reviewer (DJ) blinded to the previous voting was used to get a consensus. Quality appraisal scoring for each study can be found in Table 3.

\section{Implications for Practice, Education, and Future Research}

Plantar heel pain, classically termed plantar fasciitis or plantar fasciopathy, is a common condition affecting both athletic and nonathletic individuals. The condition often is a chronic problem, with mean symptom durations reported between 13.3 and 14.1 months. ${ }^{9,10}$ Given the high prevalence and persistence of symptoms in many individuals, it is important to identify possible factors contributing to the condition. In each study evaluated in this review, when compared to a control group, individuals with plantar heel pain demonstrated reduced PPT locally and at a remote pain-free site, suggesting the presence of altered central pain processing in some capacity.

A number of conditions with local pain reports have been linked to altered central pain processing, such as patellofemoral pain. ${ }^{11} \mathrm{~A}$ substantial percentage of individuals with patellofemoral pain $\left(57 \%\right.$ in 1 study) ${ }^{12}$ complain of persistent pain despite extensive research guiding best practice. Less than optimal outcomes may be linked to movement coordination impairments, muscle performance deficits, mobility impairments, or an inability

Table 1 Best Evidence

\begin{tabular}{lcl}
\hline Author & $\begin{array}{c}\text { Level of } \\
\text { evidence }\end{array}$ & Study design \\
\hline Fernandez-Lao, Pain Med, 2016 & 4 & Case control \\
Plaza-Manzano, J Pain, 2019 & 4 & Case control \\
Riel, Scand J Pain, 2020 & 4 & Case control \\
Ríos-León, J Orthop Sports Phys & 4 & Case control \\
Ther, 2019 & & \\
\hline
\end{tabular}




\begin{tabular}{|c|c|c|c|c|}
\hline Primary author & Fernandez-Lao, $2016^{6}$ & Plaza-Manzano, 20198 & Riel, $2020^{5}$ & Ríos-Leon, 20197 \\
\hline Title & $\begin{array}{l}\text { Assessment of pressure pain } \\
\text { hypersensitivity, ultrasound } \\
\text { image, and quality of life in } \\
\text { patients with chronic plantar } \\
\text { pain: a preliminary study }\end{array}$ & $\begin{array}{l}\text { Widespread pressure pain } \\
\text { hypersensitivity in } \\
\text { musculoskeletal and nerve } \\
\text { trunk areas as a sign of altered } \\
\text { nociceptive processing in } \\
\text { unilateral PHP }\end{array}$ & $\begin{array}{l}\text { Local hyperalgesia, normal } \\
\text { endogenous modulation with } \\
\text { pain report beyond its origin: } \\
\text { a pilot study prompting } \\
\text { further exploration into } \\
\text { plantar fasciopathy }\end{array}$ & $\begin{array}{l}\text { Topographical pressure pain } \\
\text { sensitivity maps of the feet } \\
\text { reveal bilateral sensitivity in } \\
\text { patients with unilateral PHP }\end{array}$ \\
\hline Study design & Case control & Case control & Case control & Case control \\
\hline Inclusion criteria & $\begin{array}{l}\text { (1) First-time primary } \\
\text { diagnosis of unilateral PHP } \\
\text { based on pain during first } \\
\text { steps after a period of rest } \\
\text { when standing long durations } \\
\text { (2) Lessened symptoms } \\
\text { during low levels of activity } \\
\text { such as walking } \\
\text { (3) Tenderness to palpation } \\
\text { around the medial calcaneal } \\
\text { tuberosity } \\
\text { (4) Radiographs ruling out } \\
\text { other diagnoses }\end{array}$ & $\begin{array}{l}\text { (1) Clinical PHP diagnosis: } \\
\text { insidious onset of sharp pain on } \\
\text { the plantar heel surface upon } \\
\text { weight-bearing after a period of } \\
\text { non-weight-bearing, heel pain } \\
\text { increasing in the morning with } \\
\text { the first step after waking up } \\
\text { and pain with palpation of the } \\
\text { proximal insertion of the plantar } \\
\text { fascia } \\
\text { (2) PHP duration }>3 \text { mo } \\
\text { (3) Unilateral symptoms } \\
\text { (4) } \geq 18 \text { y old }\end{array}$ & $\begin{array}{l}\text { (1) PHP for } \geq 3 \text { mo before } \\
\text { enrollment } \\
\text { (2) Average PHP intensity } \geq 2 \\
\text { on an 11-point numerical rating } \\
\text { scale during the previous week } \\
\text { (3) Thickness of the plantar } \\
\text { fascia } \geq 4.0 \mathrm{~mm} \text { measured by } \\
\text { ultrasonography } \\
\text { (4) Pain with palpation of the } \\
\text { medial calcaneal tubercle or the } \\
\text { proximal plantar fascia }\end{array}$ & $\begin{array}{l}\text { (1) Clinical PHP diagnosis: } \\
\text { insidious onset of sharp pain } \\
\text { on the plantar heel surface } \\
\text { upon weight-bearing after a } \\
\text { period of non-weight-bearing, } \\
\text { heel pain increased in the } \\
\text { morning with the first step } \\
\text { after waking up, and pain with } \\
\text { palpation of the proximal } \\
\text { insertion of the plantar fascia } \\
\text { (2) PHP duration } \geq 3 \text { mo } \\
\text { (3) Unilateral symptoms } \\
\text { (4) } \geq 18 \text { y old }\end{array}$ \\
\hline Participants & $\begin{array}{l}\mathrm{n}=44(22 \text { females }) \\
\text { PHP group: } \mathrm{n}=22, \text { mean age: } \\
47.9 \text { (11.0) y } \\
\text { Control group: } \mathrm{n}=22, \text { mean } \\
\text { age: } 47.2(11.1) \mathrm{y} \\
\text { *BMI not reported }\end{array}$ & $\begin{array}{l}\mathrm{n}=70 \text { ( } 34 \text { females) } \\
\text { PHP group: } \mathrm{n}=35, \text { mean age: } \\
41.7 \text { (37.5-45.9) } \mathrm{y} \\
\text { Control group: } \mathrm{n}=35, \text { mean } \\
\text { age: } 40.0(35.9-44.1) \mathrm{y} \\
\text { *BMI significantly higher in } \\
\text { PHP group }(P<.01)\end{array}$ & $\begin{array}{l}\mathrm{n}=27(18 \text { females }) \\
\text { PHP group: } \mathrm{n}=16, \text { median } \\
\text { age (IQR): } 47.0(9.4) \text { y } \\
\text { Control group: } \mathrm{n}=11, \text { median } \\
\text { age: } 45.7(12.8) \text { y } \\
\text { *BMI significantly higher in } \\
\text { PHP group }(P<.002)\end{array}$ & $\begin{array}{l}\mathrm{n}=70 \text { ( } 34 \text { females) } \\
\text { PHP group: } \mathrm{n}=35 \text {, mean age: } \\
42(10) \mathrm{y} \\
\text { Control group: } \mathrm{n}=35 \text {, mean } \\
\text { age: } 41 \text { (11) y } \\
\text { *BMI significantly higher in } \\
\text { PHP group }(P=.04)\end{array}$ \\
\hline $\begin{array}{l}\text { Assessment of } \\
\text { altered central } \\
\text { pain processing }\end{array}$ & PPT & PPT & $\begin{array}{l}\text { PPT, CPM, CPT, HPT, pain } \\
\text { diagram }\end{array}$ & PPT \\
\hline Testing sites & $\begin{array}{l}\text { (1) Origin of plantar fascia } \\
\text { (calcaneus bone) } \\
\text { (2) A point in the middle of } \\
\text { the plantar fascia } \\
\text { (3) First metatarsal } \\
\text { (4) Fifth metatarsal at the } \\
\text { insertion of the plantar fascia } \\
\text { (5) Soleus muscle belly } \\
\text { (6) C5-C6 zygoapophyseal } \\
\text { joint } \\
\text { (7) Second metacarpal }\end{array}$ & $\begin{array}{l}\text { (1) Origin of plantar fascia } \\
\text { (calcaneus bone) } \\
\text { (2) Medial gastrocnemius } \\
\text { muscle belly (midpoint) } \\
\text { (3) Tibialis anterior muscle } \\
\text { belly (upper third) } \\
\text { (4) Second metacarpal } \\
\text { (5) Median nerve trunk in the } \\
\text { cubital fossa } \\
\text { (6) Ulnar nerve trunk in the } \\
\text { cubital tunnel } \\
\text { (7) Radial nerve trunk at the } \\
\text { triceps intramuscular septum } \\
\text { (8) Common peroneal nerve } \\
\text { trunk posterior to the fibular } \\
\text { head } \\
\text { (9) Tibial nerve trunk at the } \\
\text { popliteal fossa } \\
\text { (10) Sural nerve trunk } \\
\text { posterolateral to the Achilles } \\
\text { myotendinous junction }\end{array}$ & $\begin{array}{l}\text { (1) Plantar heel } \\
\text { (2) Ipsilateral elbow }\end{array}$ & $\begin{array}{l}\text { (1) First metatarsal } \\
\text { (2) Third metatarsal } \\
\text { (3) Fifth metatarsal } \\
\text { (4) Abductor digiti minimi } \\
\text { muscle belly } \\
\text { (5) Flexor digitorum brevis } \\
\text { muscle belly } \\
\text { (6) Calcaneus bone }\end{array}$ \\
\hline Main findings & $\begin{array}{l}\text { PPT values were significantly } \\
\text { lower bilaterally at all testing } \\
\text { points in patients with PHP } \\
\text { compared with the control } \\
\text { group }(P<.001) \text {. There was a } \\
\text { significant interaction } \\
\text { between group and side for } \\
\text { PPT at the calcaneus bone } \\
(F=4.723, P \leq .033)\end{array}$ & $\begin{array}{l}\text { ANCOVA revealed lower } \\
\text { PPT at nerve trunks and } \\
\text { musculoskeletal structures in } \\
\text { persons with PHP compared } \\
\text { with controls }(P<.001) \text {. } \\
\text { Female patients showed } \\
\text { lower PPT than male patients } \\
\text { in almost all points }(P<.001) \text {. } \\
\text { Significant between group } \\
\text { differences in nerve trunk } \\
\text { sensitivity were found but not } \\
\text { between sides }\end{array}$ & $\begin{array}{l}\text { The PHP group demonstrated } \\
\text { lower PPTs at the plantar heel } \\
\text { (effect size; } d=1.8 \text { ), the } \\
\text { lateral elbow (effect size; } \\
d=0.7 \text { ) compared with } \\
\text { controls. Effect sizes for the } \\
\text { thermal pain thresholds } \\
\text { ranged from very small to } \\
\text { medium (CPT: } d=0.1-0.5 \text {; } \\
\text { HPT: } d=0.2-0.5 \text { ). There was } \\
\text { no difference in CPM } \\
\text { between groups. Half of the } \\
\text { PHP group self-reported } \\
\text { widespread pain extending } \\
\text { beyond the plantar heel }\end{array}$ & $\begin{array}{l}\text { Subjects with PHP } \\
\text { demonstrated lower PPTs } \\
\text { bilaterally at all assessed } \\
\text { points when compared with } \\
\text { healthy controls }(P<.001) \text {. } \\
\text { Female subjects had lower } \\
\text { PPTs than male subjects in all } \\
\text { locations }(P<.001)\end{array}$ \\
\hline
\end{tabular}


Table 2 (continued)

\begin{tabular}{|c|c|c|c|c|}
\hline Primary author & Fernandez-Lao, $2016^{6}$ & Plaza-Manzano, $2019^{8}$ & Riel, $2020^{5}$ & Ríos-León, $2019^{7}$ \\
\hline Level of evidence & IV & IV & IV & IV \\
\hline $\begin{array}{l}\text { Quality score } \\
\text { (NOS) }\end{array}$ & $9 / 9$ & $9 / 9$ & $9 / 9$ & $9 / 9$ \\
\hline Conclusion & $\begin{array}{l}\text { Patients with chronic PHP } \\
\text { exhibited bilateral and } \\
\text { widespread hypersensitivity } \\
\text { compared with healthy } \\
\text { controls }\end{array}$ & $\begin{array}{l}\text { Patients with unilateral PHP } \\
\text { demonstrated widespread } \\
\text { pressure pain hypersensitivity } \\
\text { over both nerve trunks and } \\
\text { musculoskeletal structures }\end{array}$ & $\begin{array}{l}\text { Patients with PHP } \\
\text { demonstrated mechanical } \\
\text { hyperalgesia at local and } \\
\text { remote sites compared with } \\
\text { controls and pain extending } \\
\text { beyond the plantar heel; } \\
\text { however, CPM was not } \\
\text { different between groups }\end{array}$ & $\begin{array}{l}\text { Patients with unilateral PHP } \\
\text { had generalized plantar region } \\
\text { pressure sensitivity bilaterally }\end{array}$ \\
\hline
\end{tabular}

Abbreviations: ANCOVA, analysis of covariance; BMI, body mass index; CPM, conditioned pain modulation; CPT, cold pressure threshold; HPT, heat pressure threshold; IQR, interquartile range; NOS, Newcastle-Ottawa Scale; PHP, plantar heel pain; PPT, pressure pain threshold.

Table 3 Newcastle-Ottawa Quality Appraisal Scale

\begin{tabular}{|c|c|c|c|c|c|c|c|c|c|c|}
\hline \multirow[b]{2}{*}{ Primary author } & \multicolumn{4}{|c|}{ Selection } & \multicolumn{2}{|c|}{ Comparability } & \multicolumn{3}{|c|}{ Exposure } & \multirow[b]{2}{*}{ Total score } \\
\hline & S1 & S2 & S3 & 54 & $\mathrm{Ca}$ & $\mathbf{C b}$ & $\mathrm{E1}$ & E2 & E3 & \\
\hline Fernandez-Lao $^{6}$ & $*$ & $*$ & $*$ & $*$ & $*$ & $*$ & $*$ & $*$ & $*$ & $9 / 9$ \\
\hline Plaza-Manzano $^{8}$ & $*$ & $*$ & $*$ & $*$ & $*$ & $*$ & $*$ & $*$ & $*$ & $9 / 9$ \\
\hline $\operatorname{Riel}^{5}$ & $*$ & $*$ & $*$ & $*$ & $*$ & $*$ & $*$ & $*$ & $*$ & $9 / 9$ \\
\hline Ríos-León ${ }^{7}$ & $*$ & $*$ & $*$ & $*$ & $*$ & $*$ & $*$ & $*$ & $*$ & $9 / 9$ \\
\hline
\end{tabular}

Abbreviations: $\mathrm{Ca}$ and $\mathrm{Cb}$, comparability of cases and controls; E1, ascertainment of exposure; E2, same method of ascertainment of cases and controls; E3, nonresponse rate; S1, adequate case definition; S2, representative of the cases; S3, selection of controls; S4, definition of controls.

to tolerate load demands. ${ }^{13}$ However, while additional research is necessary, persistent symptoms with peripheral conditions may be related to targeted interventions not appropriately matching the predominant pain mechanisms at fault. ${ }^{14}$ Similarly, plantar heel pain is notorious for having an extended symptom duration. The plantar fascia is consistently strained during weight-bearing activities, ${ }^{15}$ yet for many individuals, prolonged weight-bearing is a functional necessity that may perpetuate symptoms. Alternatively, the presence of sensitized nociceptive pathways or impaired descending pain modulation may contribute to the persistence of pain, ${ }^{16}$ suggesting that an investigation into pain processing in plantar heel pain is necessary.

In the athletic population, having persistent pain in weightbearing activities can substantially limit performance capacity. There are numerous factors that play a role in return to play, whether physical, psychological, or externally driven. A variety of modes of exercise can reduce pain in people with plantar heel pain; however, exercise commonly prescribed for athletes in or out of season may not have systemic analgesic effects. ${ }^{17,18}$ Without addressing pain processing or descending inhibitory pathways, exercise may offer a temporary benefit, but long-term symptom modification may be limited. The findings of this review have important clinical implications, because if athletes are found to have altered pain processing, a multimodal approach integrating additional interventions should be used rather than strictly addressing the peripheral tissue(s) at fault. ${ }^{14}$

To clinically evaluate for altered central pain processing, PPT can be measured using a pressure algometer. The device is gradually and progressively directed toward the target tissue until the patient/client subjectively reports pain. With primarily peripherally presenting conditions, such as plantar heel pain, local pressure sensitivity is expected. ${ }^{19}$ However, when PPT values are lower than available normative data at a matched site contralaterally or at a remote painfree site, the individual likely has dysfunction centrally with pain processing in addition to peripherally at the target tissue. ${ }^{20}$ With appropriate equipment, PPT can be easily measured in the clinical setting using an algometer or hand-held dynamometer, with goodexcellent interrater and intrarater reliability reported. ${ }^{21,22}$

In each study reviewed, PPT was significantly reduced at the involved foot in the plantar heel group compared to controls. Compared to the control groups, PPT was also significantly lower in the hand and neck (remote pain-free points) of the plantar heel group in 2 studies ${ }^{6,8}$ and the contralateral foot in 3 studies. $^{6-8}$ In one study, ${ }^{5}$ PPT values were lower in the plantar heel pain group with a medium effect size (0.7) but not at a level of statistical significance. The same authors found that half of the individuals with heel pain reported widespread pain on their body charts; however, no significant between-groups differences were found in heat or cold thresholds or conditioned pain modulation. This suggests that pain processing in this population may be more sensitive to specific stimuli (ie, in this population, mechanical stimuli), but not to all stimuli or through descending pain modulation. ${ }^{5}$ In addition, 2 studies found females to have statistically significant lower PPT compared to males, implying that widespread hyperalgesia in this population may be correlated to gender. ${ }^{7,8}$ Identification of peripheral versus central nociceptive pathway sensitization in plantar heel pain would benefit from additional studies incorporating similar testing protocols.

While PPT was a measure of QST consistently found to be reduced locally and remotely in each study, results should 
be interpreted with caution. Identifying central pain processing dysfunction in humans is challenging, so the use of multiple testing modalities is preferred in this detection. In the included studies, 3 studies used PPT as the primary assessment of central pain processing, ${ }^{6-8}$ while one study used additional QST measures. ${ }^{5}$ Additionally, the demographics of participants should be considered. Elevated body mass index (BMI) has been reported to be a risk factor in developing plantar heel pain. ${ }^{23}$ In this review, 1 of the 4 studies did not report BMI or enough data to calculate BMI, ${ }^{7}$ and in 3 of the 4 studies, the chronic plantar heel pain group had significantly higher BMI than the controls. ${ }^{5,6,8}$ While plantar heel pain is common in the athletic and nonathletic populations, it is possible that participant morphology also plays a role in the results. Similarly, it is important to consider many variables that affect central sensitization or nociplastic pain presentations. For example, negative psychological variables have been linked to common peripheral overuse conditions of patellofemoral pain and tendinopathy. ${ }^{24,25}$ The role of psychological variables in plantar heel pain should be examined.

Based on the results of this review, there is preliminary evidence to suggest that central pain processing may be altered in individuals with chronic plantar heel pain. Despite its peripheral presentation, clinicians should not discount the possibility of altered central pain processing in the plantar heel pain population. Additional research into pain input and processing mechanisms associated with plantar heel pain is warranted.

\section{Acknowledgments}

The authors declare no conflicts of interest.

\section{References}

1. Saggini R, Migliorini M, Carmignano SM, Ancona E, Russo C, Bellomo RG. Inferior heel pain in soccer players: a retrospective study with a proposal for guidelines of treatment. BMJ Open Sport Exerc Med. 2018;4(1):e000085-000085. eCollection 2018. PubMed ID: 29527319 doi:10.1136/bmjsem-2015-000085

2. Hotta T, Nishiguchi S, Fukutani N, et al. The association between plantar heel pain and running surfaces in competitive long-distance male runners. J Sports Med Phys Fitness. 2016;56(9):1021-1025. PubMed ID: 25942013

3. Riel H, Lindstrom CF, Rathleff MS, Jensen MB, Olesen JL. Prevalence and incidence rate of lower-extremity tendinopathies in a Danish general practice: a registry-based study. BMC Musculoskelet Disord. 2019;20(1):239-6. PubMed ID: 31113484 doi:10.1186/ s12891-019-2629-6

4. Babatunde OO, Legha A, Littlewood C, et al. Comparative effectiveness of treatment options for plantar heel pain: a systematic review with network meta-analysis. Br J Sports Med. 2019;53(3):182-194. PubMed ID: 29954828 doi:10.1136/bjsports-2017-098998

5. Riel H, Plinsinga ML, Mellor R, Boudreau SA, Vuvan V, Vicenzino B. Local hyperalgesia, normal endogenous modulation with pain report beyond its origin: a pilot study prompting further exploration into plantar fasciopathy. Scand J Pain. 2020;20(2):375-385. PubMed ID: 31541604 doi:10.1515/sjpain-2019-0109

6. Fernandez-Lao C, Galiano-Castillo N, Cantarero-Villanueva I, Martin-Martin L, Prados-Olleta N, Arroyo-Morales M. Analysis of pressure pain hypersensitivity, ultrasound image, and quality of life in patients with chronic plantar pain: a preliminary study. Pain Med. 2016;17(8):1530-1541. PubMed ID: 26814301
7. Ríos-León M, Ortega-Santiago R, Madeleine P, Fernández-deLas-Peñas C, Plaza-Manzano G. Topographical pressure pain sensitivity maps of the feet reveal bilateral pain sensitivity in patients with unilateral plantar heel pain. J Orthop Sports Phys Ther. 2019; 49(9):640-646. PubMed ID: 30913970 doi:10.2519/jospt.2019.8813

8. Plaza-Manzano G, Ríos-León M, Martín-Casas P, Arendt-Nielsen L, Fernández-de-Las-Peñas C, Ortega-Santiago R. Widespread pressure pain hypersensitivity in musculoskeletal and nerve trunk areas as a sign of altered nociceptive processing in unilateral plantar heel pain. J Pain. 2019;20(1):60-67. PubMed ID: 30121357 doi:10.1016/j. jpain.2018.08.001

9. Klein SE, Dale AM, Hayes MH, Johnson JE, McCormick JJ, Racette BA. Clinical presentation and self-reported patterns of pain and function in patients with plantar heel pain. Foot Ankle Int. 2012;33(9): 693-698. PubMed ID: 22995253 doi:10.3113/FAI.2012.0693

10. Yi TI, Lee GE, Seo IS, Huh WS, Yoon TH, Kim BR. Clinical characteristics of the causes of plantar heel pain. Ann Rehabil Med. 2011;35(4):507-513. PubMed ID: 22506166 doi:10.5535/arm.2011. 35.4.507

11. De Oliveira Silva D, Rathleff MS, Petersen K, Azevedo FM, Barton CJ. Manifestations of pain sensitization across different painful knee disorders: a systematic review including meta-analysis and metaregression. Pain Med. 2019;20(2):335-358. PubMed ID: 30423181 doi:10.1093/pm/pny 177

12. Lankhorst NE, van Middelkoop M, Crossley KM, et al. Factors that predict a poor outcome 5-8 years after the diagnosis of patellofemoral pain: a multicentre observational analysis. Br J Sports Med. 2016; 50(14):881-886. PubMed ID: 26463119 doi:10.1136/bjsports-2015094664

13. Willy RW, Hoglund LT, Barton CJ, et al. Patellofemoral pain. $J$ Orthop Sports Phys Ther. 2019;49(9):CPG1-CPG95. PubMed ID: 31475628 doi:10.2519/jospt.2019.0302

14. Chimenti RL, Frey-Law LA, Sluka KA. A mechanism-based approach to physical therapist management of pain. Phys Ther. 2018; 98(5):302-314. PubMed ID: 29669091 doi:10.1093/ptj/pzy030

15. Bolgla LA, Malone TR. Plantar fasciitis and the windlass mechanism: a biomechanical link to clinical practice. J Athl Train. 2004;39(1): 77-82. PubMed ID: 16558682

16. Woolf CJ. Central sensitization: implications for the diagnosis and treatment of pain. Pain. 2011;152(Suppl):S2. doi:10.1016/j.pain. 2010.09.030

17. Riel H, Jensen MB, Olesen JL, Vicenzino B, Rathleff MS. Self-dosed and pre-determined progressive heavy-slow resistance training have similar effects in people with plantar fasciopathy: a randomised trial. J Physiother. 2019;65(3):144-151. PubMed ID: 31204294 doi:10. 1016/j.jphys.2019.05.011

18. Riel H, Vicenzino B, Jensen MB, Olesen JL, Holden S, Rathleff MS. The effect of isometric exercise on pain in individuals with plantar fasciopathy: a randomized crossover trial. Scand J Med Sci Sports. 2018;28(12):2643-2650. PubMed ID: 30203866 doi:10.1111/sms. 13296

19. Courtney CA, Kavchak AE, Lowry CD, O'Hearn MA. Interpreting joint pain: quantitative sensory testing in musculoskeletal management. J Orthop Sports Phys Ther. 2010;40(12):818-825. PubMed ID: 20972347 doi:10.2519/jospt.2010.3314

20. Rolke R, Baron R, Maier C, et al. Quantitative sensory testing in the German Research Network on Neuropathic Pain (DFNS): standardized protocol and reference values. Pain. 2006;123(3):231-243. PubMed ID: 16697110 doi:10.1016/j.pain.2006.01.041

21. Walton DM, Macdermid JC, Nielson W, Teasell RW, Chiasson M, Brown L. Reliability, standard error, and minimum detectable change of clinical pressure pain threshold testing in people with and without 
acute neck pain. J Orthop Sports Phys Ther. 2011;41(9):644-650. PubMed ID: 21885906 doi:10.2519/jospt.2011.3666

22. Jayaseelan DJ, Cole KR, Courtney CA. Hand-Held dynamometer to measure pressure pain thresholds: a double-blinded reliability and validity study. Musculoskelet Sci Pract. 2020:102268. doi:10.1016/j. msksp.2020.102268

23. Franceschi F, Papalia R, Paciotti M, et al. Obesity as a risk factor for tendinopathy: a systematic review. Int J Endocrinol. 2014;2014:1. PubMed ID: 25214839 doi:10.1155/2014/670262
24. Maclachlan LR, Collins NJ, Matthews MLG, Hodges PW, Vicenzino B. The psychological features of patellofemoral pain: a systematic review. Br J Sports Med. 2017;51(9):732-742. PubMed ID: 28320733 doi:10.1136/bjsports-2016-096705

25. Mallows A, Debenham J, Walker T, Littlewood C. Association of psychological variables and outcome in tendinopathy: a systematic review. Br J Sports Med. 2017;51(9):743-748. PubMed ID: 27852585 doi:10.1136/bjsports-2016-096154 